\title{
Evaluation of impact-shock on gait after the implementation of two different training programs in older adults
}

\author{
Roberto Sanchis-Sanchis ${ }^{\mathrm{a}}$, Cristina Blasco-Lafarga ${ }^{\mathrm{b}}$, Andrés Camacho-García ${ }^{\mathrm{c}}$, \\ Alberto Encarnación-Martínez ${ }^{\mathrm{a}}$, Pedro Pérez-Soriano ${ }^{\mathrm{a}, *}$ \\ ${ }^{a}$ Research Group in Sports Biomechanics (GIBD), Department of Physical Education and Sports, University of Valencia, Valencia, Spain \\ ${ }^{\mathrm{b}}$ Sport Performance and Physical Fitness Research Group (UIRFIDE), Department of Physical Education and Sports, University of Valencia, Valencia, Spain \\ ${ }^{\mathrm{c}}$ Departamento de Comunicaciones, Universitat Politècnica de València, Alcoy, Spain
}

\section{A R T I C L E IN F O}

\section{Keywords:}

Elderly

Exercise

Accelerometry

Attenuation

Walking

\begin{abstract}
A B S T R A C T
Background: Gait is negatively affected with increasing age. It is widely accepted that training produces physical-functional improvements in older adults, which can be assessed with numerous physical-functional tests. However, very few studies have been carried out using accelerometry to analyse the training effect on kinetic and kinematic variables in older adults, and there is no one that investigate the effects of two different training programs. Therefore, the aim of this study is to analyse the effects of an interval-walking program and a multicomponent program on the acceleration impacts, shock attenuation, step-length, stride frequency, and gait speed in older adults.

Methods: 23 participants were divided into multicomponent training group $[n=12,7$ female, 71.58 (4.56) years] and interval-walking group $[n=11,6$ female, 69.64 (3.56) years]. We evaluated the participants using three triaxial accelerometers, placing one on the distal end of each tibia and one on the forehead.

Findings: After 14 weeks' of training, the maximum acceleration values both for the head accelerometer and for the non-dominant tibia, as well as the attenuation in the same leg, increased in the multicomponent training group. The maximum acceleration values for the head and the stride frequency also increased in the intervalwalking group. Lower limb strength improved in both groups.

Interpretation: Given the benefits we found for each of these programs, we encourage their consideration when planning older adults training programs and suggest that multicomponent programs should be introduced prior to the start of walking-based programs.
\end{abstract}

\section{Introduction}

Gait is negatively affected with increasing age because of the associated decrease in locomotor system control and coordination (Kobsar et al., 2014; Rosso et al., 2013; Seidler et al., 2010). These gait disturbances can result in serious consequences, the most notorious of which are falls, usually caused by an underlying gait problem (Snijders et al., 2007). Consequently, older adults acquire more conservative gait-adaptability strategies in kinematic terms, such a decrease in gait speed, frequency and step length (Caetano et al., 2016; Hortobágyi et al., 2009; Menz et al., 2003; Pirker and Katzenschlager, 2017). In addition, as a compensatory strategy to maintain balance after a physiological function deficit and a reduction in lower-limb strength, the acceleration magnitude also reduces in the head and pelvis (Kavanagh and Menz, 2008; Menz et al., 2003), walking with a stiffer upper body in order to try to reduce the maximum accelerations around the initial contact of the foot with the ground (Kavanagh et al., 2004).

It is widely accepted that training produces physical-functional improvements in older adults. Specific programs based on balance (Low et al., 2017) and/or strength exercises (Gray et al., 2018), as well as multicomponent training (Levy et al., 2018) and/or walking-based programs (Malatesta et al., 2010) have been shown to effectively improve static-dynamic balance, agility, postural control, lower limb strength, or gait speed in these population types (Chodzko-Zajko et al., 2009).

Numerous tests are also widely used to assess the physical-functional aspects directly related to gait in older adults. These include the Chair Stand Test to assess lower limb strength and the 8-ft Up-and-Go Test for agility and dynamic balance (Rikli and Jones, 2013). However, these evaluation systems do not provide direct quantitative data, such

\footnotetext{
* Corresponding author: Department of Physical Education and Sports, University of Valencia, C/ Gascó Oliag, nº 3., Valencia 46010, Spain.

E-mail address: pedro.perez-soriano@uv.es (P. Pérez-Soriano).
} 
as step length and stride frequency, acceleration magnitude, and/or information about shock attenuation (Kavanagh and Menz, 2008). Moreover, these kinetic and kinematic variables are directly related to gait quality and are age-related (Menz et al., 2003; Prince et al., 1997), so the analysis of the effects that training programs have on them is particularly interesting and can be used in order to try to verify the effects of training in older adults.

Because accelerometry devices are small, objective, and have a high data-storage capacity, these techniques are facilitating the evaluation of different variables of interest in the human gait (Kavanagh and Menz, 2008; Kobsar et al., 2014). However, although this kind of analysis is widely used in adults (Cheung et al., 2018; Pérez-Soriano et al., 2018; Rice et al., 2018), very few studies have been carried out to analyse the training effect on kinetic and kinematic variables in older adults. Therefore, accelerometry is a very useful and novel tool for evaluating gait in these individuals.

Thus, the aim of this study was to analyse the effects of two different types of training (multicomponent and interval-walking programs) on the acceleration impact, attenuation, stride frequency, step length, and speed during walking in older adults.

\section{Methods}

\subsection{Participants}

This study included 23 older adults [10 men and 13 women, age 70.65 (4.14) years, height 160.09 (8.96) cm, weight 79.68 (12.99) kg]. The inclusion criteria were: (1) age $\geq 65$ years; (2) individuals with no walking difficulties and who did not use any walking aids; (3) 6-m gait speed $\geq 0.8 \mathrm{~m} / \mathrm{s}$ (Cesari et al., 2005), that is, low risk of health adverse outcomes (Abellan Van Kan et al., 2009); (4) not receiving any physiotherapeutic rehabilitation or occupational therapy treatments; (5) not participating in any other physical exercise programs; (6) the absence of any cognitive impairment, that is, a Mini-Mental Score Examination Test (MMSE) score $\geq 24$ points (Lobo et al., 1999). And the exclusion criteria were: (1) pathology incompatible with the practice of regular physical activity; (2) musculoskeletal injuries in the last 6 months; (3) missing 4 or more consecutive training sessions (participant was excluded from the data analysis); (4) total attendance less than $80 \%$. Once both training programs finished, a participant from IWG was excluded because his attendance was less than $80 \%$. So, total attendance was $90 \%$ in MCG and $89 \%$ in IWG.

All our experiments complied with the ethical principles set out in the Declaration of Helsinki and were approved by the University Ethics Committee (reference number: H1478084714217) before commencing. The patients we recruited to the study gave their written informed consent before participating in it.

\subsection{Study design}

Participants were divided into two experimental groups: the multicomponent program group (MCG) comprising 12 participants, and the interval-walking group (IWG) comprising 11 participants. A homogeneous sample distribution method was used (Table 1) according to the following criteria: age, gender, weight, height, 6-m gait speed (Cesari et al., 2005), and lower-limb strength using the Five-repetition sit-to-stand test (Bohannon et al., 2010). Each group carried out one of the training programs for 14 weeks and both groups were evaluated both before participating in the program (pre-training) and after its end (post-training).

The MCG trained twice a week for approximately $60 \mathrm{~min}$ each session, carrying out the EFAM-UV(C program (Blasco-Lafarga et al., 2016), a neuromotor and cognitive multicomponent training program based on dual-tasking, gait re-education, rhythm, and strength exercises (Roldán et al., 2019). The sessions started with a neuromuscular activation based on postural control tasks during gait exercises (motor
Table 1

Demographic data of the groups of subjects.

\begin{tabular}{lccc}
\hline & MCG $(n=12)$ & IWG $(n=11)$ & $p$ \\
\hline Age (years) & $71.58(4.56)$ & $69.64(3.56)$ & $0.27^{\mathrm{a}}$ \\
Gender (male/female) & $5 / 7$ & $5 / 6$ & $0.86^{\mathrm{b}}$ \\
Weight (kg) & $79.03(16.84)$ & $80.40(7.62)$ & $0.81^{\mathrm{a}}$ \\
Height (m) & $1.57(0.09)$ & $1.63(0.09)$ & $0.13^{\mathrm{a}}$ \\
6-m Gait Speed (m/s) & $1.31(0.19)$ & $1.37(0.22)$ & $0.50^{\mathrm{a}}$ \\
5rep-StS (s) & $13.18(2.74)$ & $12.98(2.29)$ & $0.85^{\mathrm{a}}$ \\
\hline
\end{tabular}

MCG: multicomponent training group. IWG: interval-walking training group; 5rep-StS = Five-repetition sit-to-stand test.

Mean (SD).

${ }^{\text {a }} p$-value of independent $t$-test.

${ }^{\mathrm{b}} p$-value of Mann-Whitney test.

coordination dual-tasks), sometimes combined with cognitive constraints to increase the demands on executive function. Then there was a second part which could include strength exercises (elastic bands and dumbbells in alternating days), plus aerobics or rhythmic exercises, again in different days and depending on periodized objectives (from strength to endurance gains). The cool down of the session included amusing and social tasks. We followed the EFAM-UV(C training guidelines designed to increase bioenergetic, neuromuscular, and cognitive participants loads by retraining or relearning processes, individually tailoring these to each participant.

The IWG performed the walking-interval training program developed by Malatesta et al. (2010), in three training sessions per week lasting an average of 41.54 (3.17) minutes per session. Although, the training intensity was controlled by the heart rate in the original program (Malatesta et al., 2010), we also controlled it in both training programs using the OMNI-Resistance Exercise Scale (OMNI-RES) adapted for Spanish-speaking older adults (Da Silva-Grigoletto et al., 2013), because rate of perceived exertion scale has been shown to be a useful tool for monitoring exercise intensity in older adults (Shigematsu et al., 2004). The OMNI-RES is a visually supported version of the perceived exertion scale ( 1 to 10 ) whose pictures represent different training intensities used to make it easier for older adults to understand the relative training intensity (Da Silva-Grigoletto et al., 2013).

Both training programs were conducted in small groups (6-8 older adults). Also, both programs were planned and were led by trainers (sport sciences degree), specialist in older adults' training.

\subsection{Gait-assessment procedure}

Three triaxial accelerometers (AcelSystem, Blautic ${ }^{\circledR}$, Spain; size: $40 \times 22 \times 12 \mathrm{~mm}$; weight: $2.5 \mathrm{~g}$; range $\pm 16 \mathrm{G}$ ) were used. One was placed on the distal end of each tibia (Lucas-Cuevas et al., 2017) with the vertical axis of the accelerometer parallel to the vertical axis of the tibia. The third one was placed on the participant's forehead, with the vertical axis of the accelerometer perpendicular to the ground. Acceleration data was recorded at a sampling rate of $281 \mathrm{~Hz}$.

Participants were instructed to walk looking forward (not down) at a 'comfortable and safe' speed (self-selected) along a 10-m straight corridor (Fig. 1) a total of 10 times per participant. The accelerometry data was recorded during the 6 central meters, considering the first and

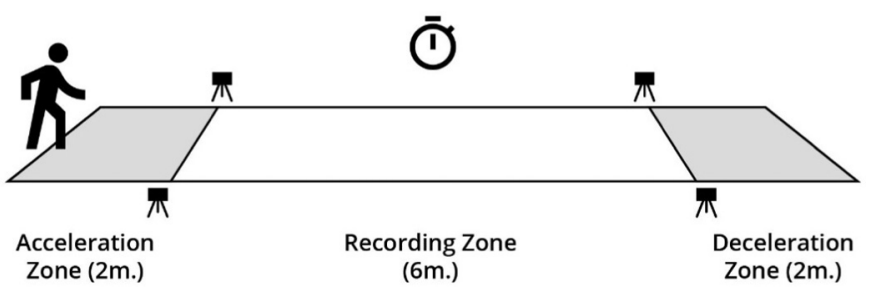

Fig. 1. Recording walkway, analysis zone. 
last $2 \mathrm{~m}$ as acceleration and deceleration zones, respectively (Kressig et al., 2006). The gait speed of each series was registered using a photocells system (Chronojump Boscosystem(C); we subsequently calculated the average speed of all the series for each participant, discarding any not within $\pm 5 \%$ of each individual's average speed (Burnfield et al., 2004), in order to minimize the effect of gait speed on the acceleration variables (Kang and Dingwell, 2008). Thus, we obtained 205 pre-training and 203 post-training series, with the analysis considering 8 steps ( 4 right leg and 4 left leg) in each trial. Thus, 1640 pre-training and 1624 post-training steps were analysed.

Data were analysed using the Matlab program (MathWorks, MA, USA), custom made. The acceleration provided by each accelerometer was corrected using a calibration file for each accelerometer and passing the acceleration on each axis through a low-pass filter (Chebyshev type II, order 8, bidirectional filter with a cut-off frequency of $20 \mathrm{~Hz}$ ). The signal was then segmented by calculating the signal period (using the autocorrelation) and locating the points of interest (maximum, minimum, etc.), respectively, for each step.

Spatio-temporal parameters (step length and stride frequency) as well as the impact-acceleration parameters - the head and tibia peak acceleration (maximal acceleration value) and shock attenuation (reduction in impact-acceleration from the tibia to the head) - were analysed from the acceleration-signal data of the vertical axis (Fig. 2), detecting the heel strikes in each leg. We also distinguished between dominant and non-dominant leg.

\subsection{Lower-limb strength assessment}

Lower-limb strength was assessed using the Five-Repetition Sit-toStand Test (Bohannon et al., 2010), due to the proved relationship between the performance in this test and lower extremity strength in older adults (Bohannon, 1995; Bohannon et al., 2010; Csuka and McCarty, 1985; McCarthy et al., 2004). From a sitting position and with the individual maintaining their arms crossed across their chest, the participant had to completely get up from a chair $(45 \mathrm{~cm}$. high, with back rest and no armrest) and sit down again 5 times in a row in the shortest time possible. We preformed the test twice per participant, with an optional rest between trials of up to $1 \mathrm{~min}$, and we considered the fastest result in our analysis. To avoid the possibility that this test could influence the normal gait pattern, it was carried out two days before to the gait assessments.

\subsection{Leg dominance determination}

Leg dominance was determined through the question "If you would shoot a ball on a target, which leg would you use to shoot the ball?", which has been shown as a reliable assessment (van Melick et al., 2017). All participants were right-footed.

\subsection{Statistical analysis}

Data were analysed with the statistics software SPSS (SPSS, Chicago, IL, USA). The normality of the variables was checked with the Kolmogorov-Smirnov test. All variables were normal, except gender (demographic data), with which we used the Mann-Whitney test. We then conducted $t$-tests for paired samples to compare the intraindividual acceleration parameters within each training group (MCG-pre vs. MCG-post; IWG-pre vs. IWG-post), setting the level for statistical significance at $P<.05$. We also calculated Cohen's $d$ effect size (Cohen, 1988; Cumming, 2012), setting the thresholds at $>0.2$ (small), > 0.5 (moderate), and $>0.8$ (large).

\section{Results}

Table 2 shows the pre- versus post-training differences in each group in terms of gait speed, step length in the dominant and nondominant leg, and stride frequency. We found a significant increase in stride frequency in the IWG $(P=.01, d=1.05)$ and there was a statistically significant reduction in the non-dominant leg step length in the MCG $(P=.02, d=0.68)$.

There was also a significant increase in the maximum head acceleration values (Fig. 3) after training in both groups, both during the support of the dominant (MCG: $P=.01, d=0.84$; IWG: $P=.01$, $d=0.73$ ) and non-dominant leg (MCG: $P=.02, d=0.68$; IWG: $P=.02, d=0.48$ ).

With respect to the maximum tibia acceleration values (Fig. 3), we
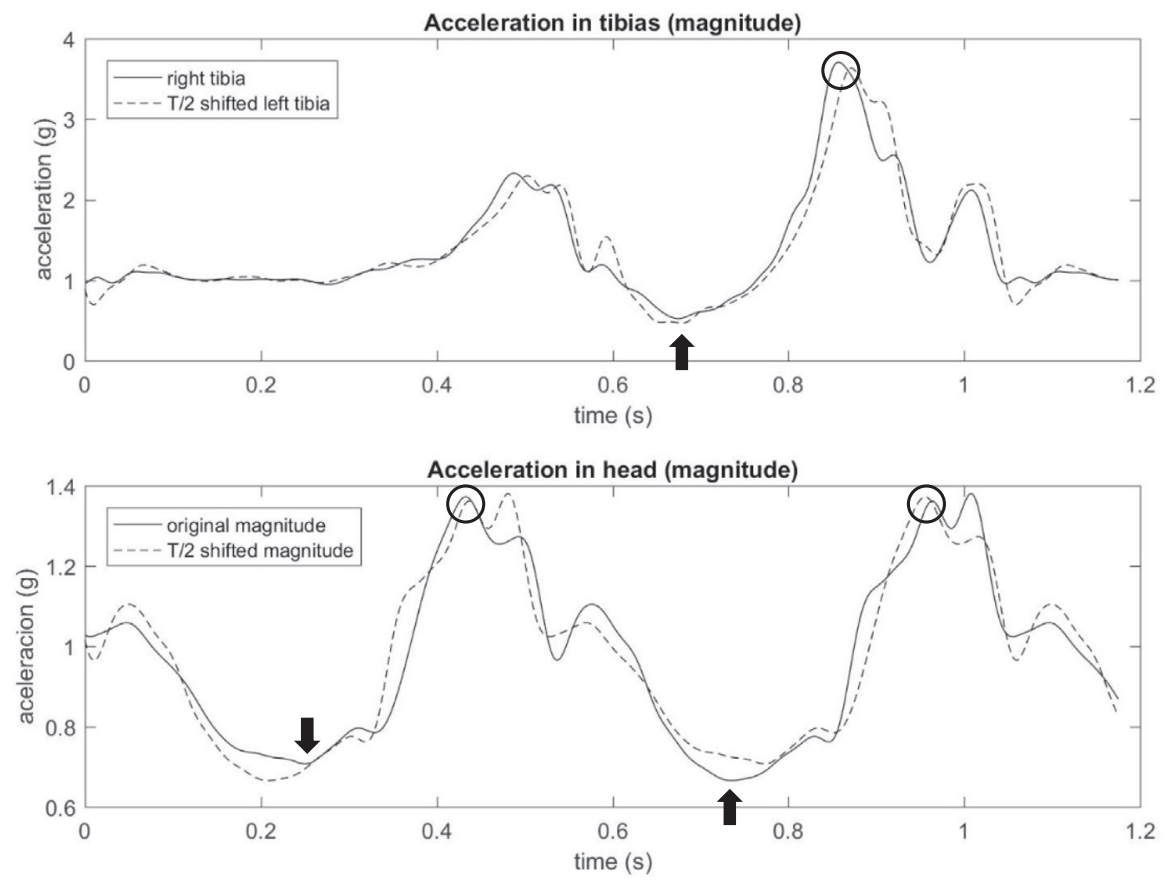

Fig. 2. Tibial and head acceleration signal. Arrow: heel strike. Ring: peak acceleration. 
Table 2

Variables analysed in dominant and non-dominant leg, before and after training programs.

\begin{tabular}{|c|c|c|c|c|c|c|c|c|}
\hline & \multicolumn{4}{|c|}{ MCG $(n=12)$} & \multicolumn{4}{|c|}{ IWG $(n=11)$} \\
\hline & pre & post & $p$ & $\mathrm{~d}$ & pre & post & $p$ & $\mathrm{~d}$ \\
\hline Gait speed (m/s) & $\begin{array}{c}1.30 \\
(0.21)\end{array}$ & $\begin{array}{c}1.23 \\
(0.28)\end{array}$ & 0.26 & 0.31 & $\begin{array}{c}1.32 \\
(0.18)\end{array}$ & $\begin{array}{c}1.44 \\
(0.25)\end{array}$ & 0.23 & 0.58 \\
\hline $\begin{array}{l}\text { Step length D } \\
\text { (m) }\end{array}$ & $\begin{array}{c}0.66 \\
(0.09)\end{array}$ & $\begin{array}{c}0.60 \\
(0.12)\end{array}$ & 0.07 & 0.60 & $\begin{array}{c}0.69 \\
(0.10)\end{array}$ & $\begin{array}{c}0.69 \\
(0.10)\end{array}$ & 0.99 & 0.01 \\
\hline $\begin{array}{l}\text { Step length ND } \\
\text { (m) }\end{array}$ & $\begin{array}{c}0.69 \\
(0.08)\end{array}$ & $\begin{array}{c}0.63 \\
(0.11)\end{array}$ & 0.02 & 0.68 & $\begin{array}{c}0.69 \\
(0.09)\end{array}$ & $\begin{array}{c}0.72 \\
(0.12)\end{array}$ & 0.45 & 0.29 \\
\hline $\begin{array}{l}\text { Stride frequency } \\
\qquad(\mathrm{Hz})\end{array}$ & $\begin{array}{c}0.95 \\
(0.09)\end{array}$ & $\begin{array}{c}0.99 \\
(0.09)\end{array}$ & 0.07 & 0.44 & $\begin{array}{c}0.95 \\
(0.05)\end{array}$ & $\begin{array}{c}1.01 \\
(0.05)\end{array}$ & 0.01 & 1.05 \\
\hline
\end{tabular}

Mean (SD); MCG: multicomponent training group; IWG: interval-walking training group; D: dominant leg; ND: non-dominant leg; bold: $p<.05$

found no significant differences in any group for the dominant leg (MCG: $P=.06, d=0.73$; IWG: $P=.55, d=0.19$ ). However, there was a significant increase in the non-dominant leg in the MCG $(P=.02$, $d=0.80)$ but not in the IWG $(P=.10, d=0.50)$.

Comparing the pre- and post-training attenuation values (Fig. 3), we found no significant differences in the dominant leg in either of the two groups (MCG: $P=.13, d=0.56$; IWG: $P=.48, d=0.26$ ). Nevertheless, there was a significant increase in the non-dominant leg in the MCG $(P<.01, d=0.69)$ but not in the IWG $(P=.29, d=0.34)$.

Finally, lower-limb strength significantly improved in both groups after completion of the training programs [MCG: 13.18 (2.74) s vs. $11.48(2.34) \mathrm{s}, P=.02, d=0.67$; IWG: $12.98(2.29) \mathrm{s}$ vs. 11.20 (1.83) s, $P=.01, d=0.86]$.

\section{Discussion}

This study aimed to analyse the effects on the acceleration impact (on the head and tibia), shock attenuation, stride frequency and step length during walking in older adults, after completing either a multicomponent training program (MCG) or an interval-walking program (IWG). In summary, MCG increased the maximum acceleration values both in the head (during support by either leg) and the non-dominant tibia, as well as improving the shock attenuation in the latter. IWG also increased the maximum acceleration values in the head (in both legs) as well as the stride frequency. In addition, lower-limb strength significantly improved in both groups.

Head and pelvis accelerations during walking are lower in older adults compared to younger adults (Kavanagh and Menz, 2008; Menz et al., 2003) due to the fact that older adults walk with a stiffer upper body trying to reduce the maximum accelerations in the initial contact of the foot with the ground (Kavanagh et al., 2004). The final head accelerations achieved in this study in both training groups and both during dominant and non-dominant leg support, suggest that physical exercise (regardless of its type) is sufficient to increase the head accelerations to more similar levels to those of younger adults. For example, in a sample of men and women aged 24.66 (3.67) years, with a walking speed similar to that of our study $(1.3 \mathrm{~m} / \mathrm{s})$, Lucas-Cuevas et al. (2013) recorded head accelerations of $2.62(0.43) \mathrm{g}$ in men and 2.83 (0.47) $\mathrm{g}$ in women. In our study, the participants' average (dominant and non-dominant leg) head accelerations increased in both groups after training (MCG: $+14.91 \%$, IWG: $+11.75 \%$ ), reaching $2.24 \mathrm{~g}$ in the MCG and $2.28 \mathrm{~g}$ in the IWG.

Lower limb dominance has an important role in gait stability (Kim and Lockhart, 2012). Moreover, dominance increases with age, and is one of the factors that causes increased strength asymmetry between a given limb and its contralateral one, which is estimated at $15 \%-20 \%$ in older adults (LaRoche et al., 2012). This asymmetry is one of the causes of the increase in the gait asymmetry common in this population, and is also higher among older adults with higher fall risks (LaRoche et al.,
2012). However, dominance can be minimised through physical exercise, especially with strength and balance training (Kim and Lockhart, 2012)—the types of exercises included in the multicomponent training program. Thus, the $41.93 \%$ increase in the maximum accelerations that we recorded in the non-dominant leg tibia in the MCG after training reinforces this idea; the acceleration magnitudes of the non-dominant leg in this group after completing the training approached those of the dominant leg (9.98 $\mathrm{g}$ and $10.51 \mathrm{~g}$, respectively).

A series of impacts are repeatedly produced during gait by the foot's contact with the floor, which can lead to degenerative injuries caused by overuse and are more common in individuals with an advanced age (Cress et al., 2006; Yamada and Thomas, 2011). The body's capacity to attenuate these impacts is decisive in the appearance of these types of injury (Coventry et al., 2006), but this attenuation also reduces with age (Bus, 2003; Prince et al., 1997). Thus, the improvement in shock attenuation achieved in this study in the MCG while supporting the non-dominant leg $(+6.91 \%, P<.01)$ is especially important for the prevention of future degenerative lesions in older adults (Bus, 2003). Although the head accelerations in both groups and in the non-dominant tibia (MCG) increased after training, the attenuation simultaneously improved in the MCG but not in the IWG, suggesting that, in contrast to the IWG, these acceleration increases will not increase the probability of injury in the MCG (dominant leg $-1.66 \%, P=.48$; nondominant leg $3.44 \%, P=.29$ ). Therefore, multicomponent training programs seem to be better at mitigating the deceleration-impact produced during gait in this population, which makes its implementation especially useful at the beginning of OA training programs. To date, this is the first study to analyse the effects of physical training on shock attenuation in older adults. Thus, these results should be considered when designing training programs for participants with a high probability of suffering degenerative injuries caused by overuse, including patients with osteoporosis or arthritis (Yamada and Thomas, 2011).

Increasing age usually results in a decrease in speed as well as a reduction in stride frequency and step length (Menz et al., 2003). However, these variables can be modified through physical activity training programs (Wang et al., 2015). In our study, neither of the training groups achieved improvements in step length in either leg; in fact, this parameter reduced in the MCG, significantly so in the nondominant leg. Muscle coactivation increases in older adults (Hortobágyi et al., 2009; Lo et al., 2017; Peterson and Martin, 2010) which has been related to a reduction in strength in advanced ages (Hortobágyi and DeVita, 2000). The lower level of muscle torque in older adults can be explained not only by smaller contractile muscle mass but also by increased coactivation of the antagonist muscles during knee extension (Macaluso et al., 2002). This coactivation increase during walking seems to be an adaptive process to the physiological changes of aging, in order to gain joint stability (Arias et al., 2012). Therefore, while lower-limb strength improved in both the training groups in our study, perhaps these improvements in the MCG did not reduce muscle coactivation enough to allow an increase in step length, or at least, to mitigate its decline. However, it is more likely that the step-education work that forms part of the EFAM-UV@ program (which focuses on improving the stopping and starting skills and on weight and directional changes, etc.) produced gait adaptations or improvements which differed to those resulting from the walking program, indicating the importance of the specific training types in adult populations. In fact, walking may involve muscle agonist-antagonist coordination work which has implications for the amplitude and the decrease of excessive antagonist-muscle activation. To verify if longer interventions could lead to greater improvements in lower-limb strength and a concurrent reduction in muscle coactivation and step length extension, or if the improvements observed result from specific programs, future studies for similar intervention types and lasting for longer periods will be required.

Although our results for speed were not statistically significant, it is worth noting that in our study the gait speed increased by $0.12 \mathrm{~m} / \mathrm{s}$ in 

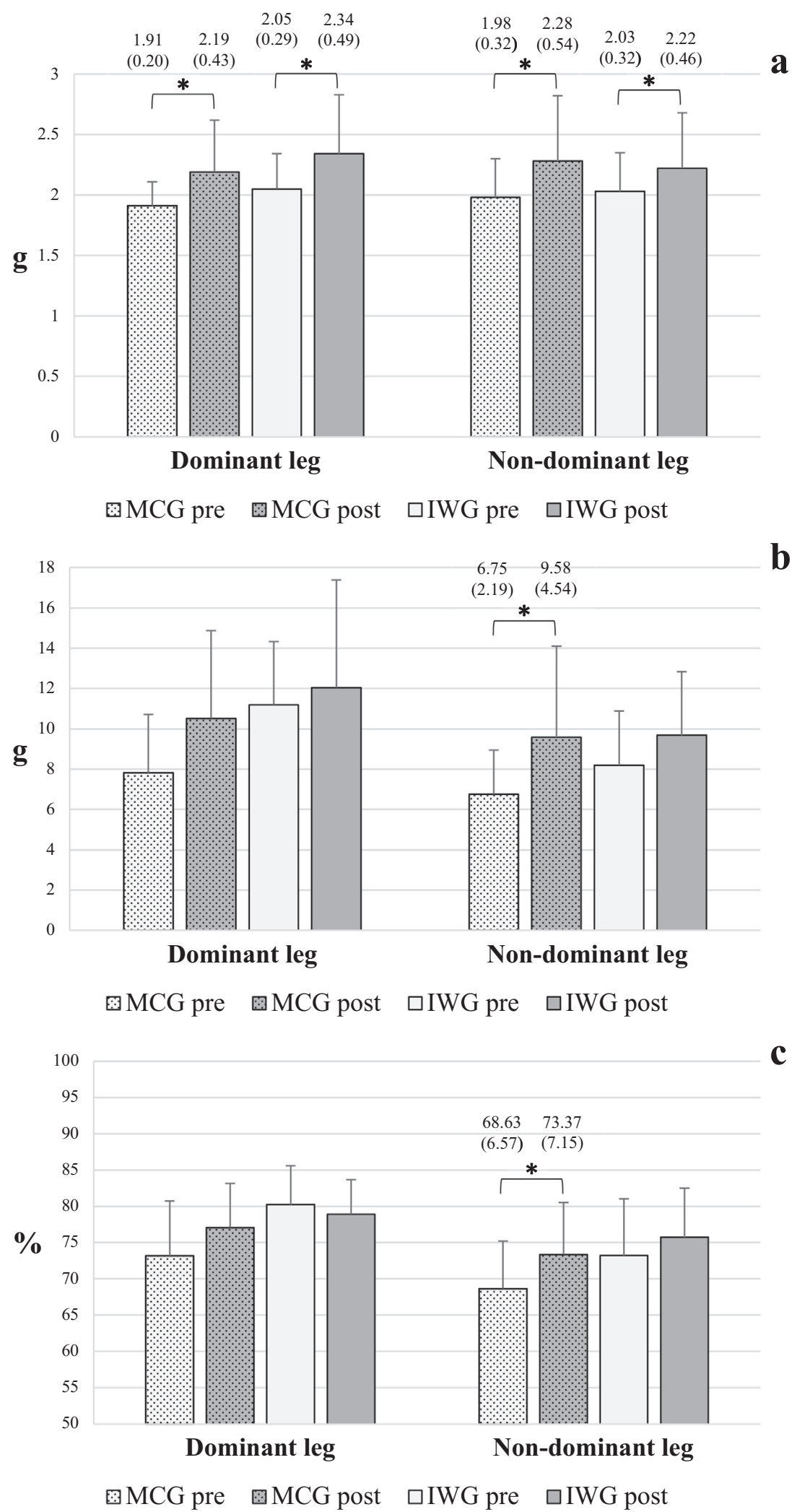

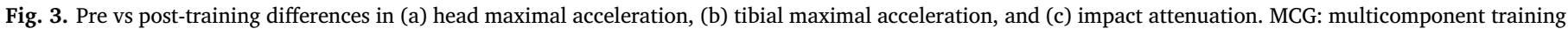
group. IWG: interval-walking training group. ${ }^{*} p<.05$.

the IWG after training. Of interest, an increase of $0.10 \mathrm{~m} / \mathrm{s}$ in gait speed in older adults reduces the risk of premature mortality by $11 \%$ (Brown et al., 2014). In addition, according to Studenski et al. (2011), this small increase equates to an increase in life expectancy of approximately 1 or 2 years in men and women, respectively. Our data regarding speed, together with the significant increase in stride frequency (or cadence) that our IWG study participants achieved after training, reinforce the conclusions of Jerome et al. (2015), that a faster cadence is related to a lower probability of declining gait speed. Again, each training program had different effects, although the effect size for stride frequency and 
speed was larger in the IWG, leading us to infer that walking programs should be maximised in older adults once their gait capacity has been educated.

Finally, this study does have some limitations. Firstly, although the step number analysed in each participant was high, both in the pretraining and post-training evaluations, analysing more participants would also be recommendable. Second, our interventions lasted for 14 weeks which, according to the American College of Sport Medicine recommendations (Chodzko-Zajko et al., 2009), places it in the middle of training program lengths classified as short (10-12 weeks) or long (21-24). However, 14 weeks may be insufficient time for major effects on the variables of interest in this study to become observable. In this sense, it might be advisable to increase the duration of the training programs used in future research studies.

\section{Conclusions}

In conclusion, after 14 training weeks, during which two different programs were implemented in two participant groups, improvements were observed in the parameters analysed during gait, as well as improvements in lower-limb strength. On the one hand, the intervalwalking program we implemented in older adults increased stride frequency, but also increased the maximum head acceleration (while supporting either leg) without improving shock attenuation. On the other hand, the multicomponent training program we studied increased maximum head acceleration (also in both legs) and in the non-dominant leg tibia, and also improved shock attenuation, although step length was reduced. Both training programs increased lower-limb strength. Thus, in the knowledge of the benefits of each training type, it may be useful to introduce firstly a multicomponent program, and subsequently, a walking-based program in older adults. However, future work will be required to verify if this periodization proposal is optimal for this population type.

\section{Funding}

This work was supported by the Valencian Government (Spain) and the European Social Fund ("European Social Fund, Investing in your Future") through a predoctoral contract to Dr. Sanchis-Sanchis; Grant number: ACIF/2016/496.

\section{Acknowledgements}

We wish to thank all the study participants.

\section{References}

Abellan Van Kan, G., Rolland, Y, Andrieu, S., Bauer, J., Beauchet, O., Bonnefoy, M., Cesari, M., Donini, L.M., Gillette-Guyonnet, S., Inzitari, M., Nourhashemi, F., Onder, G., Ritz, P., Salva, A., Visser, M., Vellas, B., 2009. Gait speed at usual pace as a predictor of adverse outcomes in community-dwelling older people an International Academy on Nutrition and Aging (IANA) Task Force. J. Nutr. Health Aging 13, 881-889. https://doi.org/10.1007/s12603-009-0246-z.

Arias, P., Espinosa, N., Robles-García, V., Cao, R., Cudeiro, J., 2012. Antagonist muscle co-activation during straight walking and its relation to kinematics: insight from young, elderly and Parkinson's disease. Brain Res. 1455, 124-131. https://doi.org/ 10.1016/j.brainres.2012.03.033.

Blasco-Lafarga, C., Martínez-Navarro, I., Cordellat, A., Roldán, A., Monteagudo-Chiner, P., Sanchis-Soler, G., Sanchis-Sanchis, R., 2016. Authors of the Intellectual Property Rights of the 'Método de Entrenamiento Funcional Cognitivo Neuromotor EFAM-UV', Under the Ownership of the University of Valencia, With Registration No. 156069, and Registration Date: 10/24/2016.

Bohannon, R.W., 1995. Sit-to-stand test for measuring performance of lower extremity muscles. Percept. Mot. Skills 80, 163-166. https://doi.org/10.2466/pms.1995.80.1 163.

Bohannon, R.W., Bubela, D.J., Magasi, S.R., Wang, Y.-C., Gershon, R.C., 2010. Sit-to-stand test: performance and determinants across the age-span. Isokinet. Exerc. Sci. 18, 235-240. https://doi.org/10.3233/IES-2010-0389.

Brown, J.C., Harhay, M.O., Harhay, M.N., 2014. Walking cadence and mortality among community-dwelling older adults. J. Gen. Intern. Med. 29, 1263-1269. https://doi. org/10.1007/s11606-014-2926-6.
Burnfield, J.M., Few, C.D., Mohamed, O.S., Perry, J., 2004. The influence of walking speed and footwear on plantar pressures in older adults. Clin. Biomech. 19, 78-84. https://doi.org/10.1016/j.clinbiomech.2003.09.007.

Bus, S.A., 2003. Ground reaction forces and kinematics in distance running in older-aged men. Med. Sci. Sports Exerc. 35, 1167-1175. https://doi.org/10.1249/01.MSS. 0000074441.55707.D1.

Caetano, M.J.D., Lord, S.R., Schoene, D., Pelicioni, P.H.S., Sturnieks, D.L., Menant, J.C., 2016. Age-related changes in gait adaptability in response to unpredictable obstacles and stepping targets. Gait Posture 46, 35-41. https://doi.org/10.1016/j.gaitpost. 2016.02.003.

Cesari, M., Kritchevsky, S.B., Penninx, Brenda W.H.J., Nicklas, B.J., Simonsick, E.M., Newman, A.B., Tylavsky, F.A., Brach, J.S., Satterfield, S., Bauer, D.C., Visser, M., Rubin, S.M., Harris, T.B., Pahor, M., 2005. Prognostic value of usual gait speed in well-functioning older people - results from the health, aging and body composition study. J. Am. Geriatr. Soc. 53, 1675-1680. https://doi.org/10.1111/j.1532-5415. 2005.53501.x.

Cheung, R.T.H., An, W.W., Au, I.P.H., Zhang, J.H., Chan, Z.Y.S., MacPhail, A.J., 2018. Control of impact loading during distracted running before and after gait retraining in runners. J. Sports Sci. 36, 1497-1501. https://doi.org/10.1080/02640414.2017. 1398886.

Chodzko-Zajko, W.J., Proctor, D.N., Fiatarone Singh, M.A., Minson, C.T., Nigg, C.R., Salem, G.J., Skinner, J.S., 2009. ACSM position stand: exercise and physical activity for older adults. Med. Sci. Sports Exerc. 41, 1510-1530. https://doi.org/10.1249/ MSS.0b013e3181a0c95c.

Cohen, J., 1988. Statistical Power Analysis for the Behavioural Sciences, 2nd ed. Lawrence Erlbaum Associates, Hillsdale, NJ.

Coventry, E., O'Connor, K.M., Hart, B.A., Earl, J.E., Ebersole, K.T., 2006. The effect of lower extremity fatigue on shock attenuation during single-leg landing. Clin. Biomech. 21, 1090-1097. https://doi.org/10.1016/j.clinbiomech.2006.07.004.

Cress, M.E., Buchner, D.M., Prohaska, T., Rimmer, J., Brown, M., Macera, C., DiPietro, L., Chodzko-Zajko, W., 2006. Best practices for physical activity programs and behavior counseling in older adult populations. Eur. Rev. Aging Phys. Act. 3, 34-42. https:// doi.org/10.1007/s11556-006-0003-9.

Csuka, M., McCarty, D.J., 1985. Simple method for measurement of lower extremity muscle strength. Am. J. Med. 78, 77-81. https://doi.org/10.1016/0002-9343(85) 90465-6.

Cumming, G., 2012. Understanding the New Statistics: Effect Sizes, Confidence Intervals, and Meta-Analysis. Routledge, New York.

Da Silva-Grigoletto, M.E., Viana-Montaner, B.H., Heredia, J.R., Mata, F., Peña, G., Brito, C.J., Vaamonde, D., García-Manso, J.M., 2013. Validación de la escala de valoración subjetiva del esfuerzo OMNI-GSE para el control de la intensidad global en sesiones de objetivos múltiples en personas mayores. Kronos 12, 32-40.

Gray, M., Powers, M., Boyd, L., Garver, K., 2018. Longitudinal comparison of low- and high-velocity resistance training in relation to body composition and functional fitness of older adults. Aging Clin. Exp. Res. https://doi.org/10.1007/s40520-018 0929-6.

Hortobágyi, T., DeVita, P., 2000. Muscle pre- and coactivity during downward stepping are associated with leg stiffness in aging. J. Electromyogr. Kinesiol. 10, 117-126. https://doi.org/10.1016/S1050-6411(99)00026-7.

Hortobágyi, T., Solnik, S., Gruber, A., Rider, P., Steinweg, K., Helseth, J., DeVita, P., 2009. Interaction between age and gait velocity in the amplitude and timing of antagonist muscle coactivation. Gait Posture 29, 558-564. https://doi.org/10.1016/j.gaitpost. 2008.12.007.

Jerome, G.J., Ko, S. uk, Kauffman, D., Studenski, S.A., Ferrucci, L., Simonsick, E.M., 2015. Gait characteristics associated with walking speed decline in older adults: results from the Baltimore Longitudinal Study of Aging. Arch. Gerontol. Geriatr. 60, 239-243. https://doi.org/10.1016/j.archger.2015.01.007.

Kang, H.G., Dingwell, J.B., 2008. Separating the effects of age and walking speed on gait variability. Gait Posture 27, 572-577. https://doi.org/10.1016/j.gaitpost.2007.07. 009.

Kavanagh, J.J., Menz, H.B., 2008. Accelerometry: a technique for quantifying movement patterns during walking. Gait Posture 28, 1-15. https://doi.org/10.1016/j.gaitpost. 2007.10.010.

Kavanagh, J.J., Barrett, R.S., Morrison, S., 2004. Upper body accelerations during walking in healthy young and elderly men. Gait Posture 20, 291-298. https://doi. org/10.1016/j.gaitpost.2003.10.004.

Kim, S., Lockhart, T., 2012. Lower limb control and mobility following exercise training. J. Neuroeng. Rehabil. 9, 1-8. https://doi.org/10.1186/1743-0003-9-15.

Kobsar, D., Olson, C., Paranjape, R., Hadjistavropoulos, T., Barden, J.M., 2014. Evaluation of age-related differences in the stride-to-stride fluctuations, regularity and symmetry of gait using a waist-mounted tri-axial accelerometer. Gait Posture 39, 553-557. https://doi.org/10.1016/j.gaitpost.2013.09.008.

Kressig, R.W., Beauchet, O., European GAITRite ${ }^{\circledast}$ Network Group, 2006. Guidelines for clinical applications of spatio-temporal gait analysis in older adults. Aging Clin. Exp. Res. 18, 174-176. https://doi.org/10.1007/BF03327437.

LaRoche, D.P., Cook, S.B., Mackala, K., 2012. Strength asymmetry increases gait asymmetry and variability in older women. Med. Sci. Sports Exerc. 44, 2172-2181. https://doi.org/10.1249/MSS.0b013e31825e1d31.

Levy, S.S., Thralls, K.J., Goble, D.J., Krippes, T.B., 2018. Effects of a community-based exercise program on older adults' physical function, activities of daily living, and exercise self-efficacy: feeling fit club. J. Appl. Gerontol. March, 0733464818760237. https://doi.org/10.1177/0733464818760237.

Lo, J., Lo, O.Y., Olson, E.A., Habtemariam, D., Iloputaife, I., Gagnon, M.M., Manor, B. Lipsitz, L.A., 2017. Functional implications of muscle co-contraction during gait in advanced age. Gait Posture 53, 110-114. https://doi.org/10.1016/j.gaitpost.2017. 01.010 . 
Lobo, A., Saz, P., Marcos, G., Día, J.L., De la Cámara, C., Ventura, T., Morales Asín, F., Pascual, L.F., Montañés, J.Á., Aznar, S., 1999. Revalidación y normalización del mini examen cognoscitivo (primera versión en castellano del mini mental status examination) en la población geriátrica general. Med. Clin. 112, 767-774.

Low, D.C., Walsh, G.S., Arkesteijn, M., 2017. Effectiveness of exercise interventions to improve postural control in older adults: a systematic review and meta-analyses of centre of pressure measurements. Sports Med. 47, 101-112. https://doi.org/10. 1007/s40279-016-0559-0.

Lucas-Cuevas, A.G., Pérez-Soriano, P., Bush, M., Crossman, A., Llana, S., Cortell-Tormo, J.M., Pérez-Turpin, J.A., 2013. Effects of different backpack loads in acceleration transmission during recreational distance walking. J. Hum. Kinet. 37, 81-89. https:// doi.org/10.2478/hukin-2013-0028.

Lucas-Cuevas, A.G., Encarnación-Martínez, A., Camacho-García, A., Llana-Belloch, S Pérez-Soriano, P., 2017. The location of the tibial accelerometer does influence impact acceleration parameters during running. J. Sports Sci. 35, 1734-1738. https:// doi.org/10.1080/02640414.2016.1235792.

Macaluso, A., Nimmo, M.A., Foster, J.E., Cockburn, M., McMillan, N.C., De Vito, G., 2002. Contractile muscle volume and agonist-antagonist coactivation account for differences in torque between young and older women. Muscle Nerve 25, 858-863. https://doi.org/10.1002/mus.10113.

Malatesta, D., Simar, D., Saad, H. Ben, Préfaut, C., Caillaud, C., 2010. Effect of an overground walking training on gait performance in healthy 65- to 80-year-olds. Exp. Gerontol. 45, 427-434. https://doi.org/10.1016/j.exger.2010.03.009.

McCarthy, E.K., Horvat, M.A., Holtsberg, P.A., Wisenbaker, J.M., 2004. Repeated chair stands as a measure of lower limb strength in sexagenarian women. Journals Gerontol. Ser. A 59, 1207-1212. https://doi.org/10.1093/gerona/59.11.1207.

van Melick, N., Meddeler, B.M., Hoogeboom, T.J., Nijhuis-van der Sanden, M.W.G., van Cingel, R.E.H., 2017. How to determine leg dominance: the agreement between selfreported and observed performance in healthy adults. PLoS One 12, 1-9. https://doi. org/10.1371/journal.pone.0189876.

Menz, H.B., Lord, S.R., Fitzpatrick, R.C., 2003. Age-related differences in walking stability. Age Ageing 32, 137-142. https://doi.org/10.1093/ageing/32.2.137.

Pérez-Soriano, P., Lucas-Cuevas, A.G., Priego-Quesada, J.I., Sanchis-Sanchis, R., Cambronero-Resta, M., Llana-Belloch, S., Oficial-Casado, F.J., Encarnación-Martínez, A., 2018. An 8-week running training program modifies impact accelerations during running. J. Athl. Enhanc. 7, 1-4. https://doi.org/10.4172/2324-9080.1000283.

Peterson, D.S., Martin, P.E., 2010. Effects of age and walking speed on coactivation and cost of walking in healthy adults. Gait Posture 31, 355-359. https://doi.org/10. 1016/j.gaitpost.2009.12.005
Pirker, W., Katzenschlager, R., 2017. Gait disorders in adults and the elderly. Wien. Klin. Wochenschr. 129, 81-95. https://doi.org/10.1007/s00508-016-1096-4.

Prince, F., Corriveau, H., Hébert, R., Winter, D.A., 1997. Gait in the elderly. Gait Posture 5, 128-135. https://doi.org/10.1016/S0966-6362(97)01118-1.

Rice, H.M., Saunders, S.C., McGuire, S.J., O'Leary, T.J., Izard, R.M., 2018. Estimates of Tibial shock magnitude in men and women at the start and end of a military drill training program. Mil. Med. 1-7. https://doi.org/10.1093/milmed/usy037. March.

Rikli, R.E., Jones, C.J., 2013. Senior Fitness Test Manual, 2nd ed. Human Kinetics, Champaign, IL.

Roldán, A., Cordellat, A., Monteagudo, P., García-Lucerga, C., Blasco-Lafarga, N.M., Gomez-Cabrera, M.C., Blasco-Lafarga, C., 2019. Beneficial effects of inspiratory muscle training combined with multicomponent training in elderly active women. Res. Q. Exerc. Sport 0, 1-8. https://doi.org/10.1080/02701367.2019.1633009.

Rosso, A.L., Studenski, S.A., Chen, W.G., Aizenstein, H.J., Alexander, N.B., Bennett, D.A., Black, S.E., Camicioli, R., Carlson, M.C., Ferrucci, L., Guralnik, J.M., Hausdorff, J.M., Kaye, J., Launer, L.J., Lipsitz, L.A., Verghese, J., Rosano, C., 2013. Aging, the central nervous system, and mobility. Journals Gerontol. Ser. A 68, 1379-1386. https://doi org/10.1093/gerona/glt089.

Seidler, R.D., Bernard, J.A., Burutolu, T.B., Fling, B.W., Gordon, M.T., Gwin, J.T., Kwak, Y., Lipps, D.B., 2010. Motor control and aging: links to age-related brain structural, functional, and biochemical effects. Neurosci. Biobehav. Rev. 34, 721-733. https:// doi.org/10.1016/j.neubiorev.2009.10.005.

Shigematsu, R., Ueno, L.M., Nakagaichi, M., Nho, H., Tanaka, K., 2004. Rate of perceived exertion as a tool to monitor cycling exercise intensity in older adults. J. Aging Phys. Act. 12.

Snijders, A.H., van de Warrenburg, B.P., Giladi, N., Bloem, B.R., 2007. Neurological gait disorders in elderly people: clinical approach and classification. Lancet Neurol. 6, 63-74. https://doi.org/10.1016/S1474-4422(06)70678-0.

Studenski, S., Perera, M.P.H.S., Patel, P.K., Rosano, P.C., Faulkner, P.K., Inzitari, P.M., Brach, P.J., Chandler, P.J., Cawthon, P.P., Connor, P.E.B., Nevitt, M.D.M., Visser, P.M., Kritchevsky, P.S., Badinelli, P.S., Harris, M.D.T., Newman, M.D.A.B., Cauley, M.D.J., Ferrucci, P.L., Guralnik, P.Jr, 2011. Gait speed and survival in older adults. JAMA 305, 50-58. https://doi.org/10.1001/jama.2010.1923.

Wang, R.-Y., Wang, Y.-L., Cheng, F.-Y., Chao, Y.-H., Chen, C.-L., Yang, Y.-R., 2015. Effects of combined exercise on gait variability in community-dwelling older adults. Age (Omaha). 37, 40. https://doi.org/10.1007/s11357-015-9780-2.

Yamada, E., Thomas, D.C., 2011. Common musculoskeletal diagnoses of upper and lower extremities in older patients. Mt. Sinai J. Med. A J. Transl. Pers. Med. 78, 546-557. https://doi.org/10.1002/msj.20274. 